\title{
Influence of half marathon race on aortic stiffness in amateur runners
}

\author{
Marzena Staniszewska, Artur Pudło, Andrzej Pawlik
}

Department of Physiology, Pomeranian Medical University, Szczecin, Poland

Submitted: 3 December 2015

Accepted: 8 March 2016

Arch Med Sci 2017; 13, 4: 962-964

DOI: https://doi.org/10.5114/aoms.2016.59580

Copyright @ 2016 Termedia \& Banach

Physical activity affects the condition of the cardiovascular system. Regular exercise has been suggested to delay or prevent an increase in arterial stiffness [1], which is an independent marker of coronary atherosclerosis and a predictor parameter of cardiovascular events and all-cause mortality [2]. However, high-intensity aerobic exercise causes systemic vascular remodeling that shifts the effect of aerobic exercise from cardioprotective to atherogenic and increases the risk of coronary heart disease [3].

A new method for determining approved indicators of cardiovascular risk is the oscillometric method, which evaluates pulse wave velocity (PWV) and central aortic pressure [4]. This method allows evaluation of elastic properties of the aorta on the basis of PWV and pulse wave reflection expressed as the aortic augmentation index (Alx) and pulse pressure amplification (PPA). These parameters are valuable for cardiovascular risk evaluation [5].

Aerobic, extremely vigorous exercise is a special challenge for cardiovascular system adaptation. Still there is insufficient knowledge about the temporary response of the vascular wall to hyperkinetic circulation. We decided to evaluate the hemodynamic response of the cardiovascular system to a half marathon race in amateur runners, in particular for the estimation of cardiovascular risk factors including arterial stiffness and parameters describing pulse wave form during recovery.

The study group consisted of healthy male amateur runners $(n=8$, age $27 \pm 2$ years, weight $77.1 \pm 7.3 \mathrm{~kg}$, height $182 \pm 8.0 \mathrm{~cm}$, body mass index (BMI) $23.2 \pm 1.3 \mathrm{~kg} / \mathrm{m}^{2}$ ). Participants were selected through medical screening before the study (according to the guidelines of the American College of Sports Medicine and pre-participation medical screening [6]).

Exclusion criteria were: age $\geq 30$ years, cardiovascular risk factors, diabetes mellitus, peripheral arterial disease, alcohol, obesity, smoking, history of vascular surgery, arrhythmia, cardiac valvulopathy or myocardial ischemia, drug treatment, and disorders in ECG.

All subjects of the study completed the full course $(21.097 \mathrm{~km})$ with a time between 1:18.22 and 1:51.45 hours.

Blood pressure and pulse waveform were evaluated in the supine position after $15 \mathrm{~min}$ of rest by means of the oscillometric method using Vasotens technology (BP Lab) [7]. The measurements were obtained on the left arm three days before the race and 30 min after the end of the half marathon race. Examination was continued until it revealed repetitive results. The peripheral arterial waveform was registered at the brachial artery during step-by-step deflation, and after "transfer function" application was used for evaluation of central aortic pressure, PWV,

\author{
Corresponding author: \\ Marzena Staniszewska \\ MD, PhD \\ Department of Physiology \\ Pomeranian Medical \\ University \\ Al. Powstańców \\ Wielkopolskich 72 \\ 70-111 Szczecin, Poland \\ Phone: +48914661611 \\ Fax: +48914661612 \\ E-mail: stanma@pum.edu.pl
}


reflected wave transit time (RWTT), and ejection duration (ED). The augmentation index set to 75 heart beats per minute (AIX75), PPA, and subendocardial viability ratio (SEVR) were analyzed from the central pulse wave form.

Statistical analysis included the Shapiro-Wilk test to confirm the normal distribution of the data. Parameters before and after the half marathon race were compared using an dependent Student's $t$ test. For parameters with a non-normal distribution, the Wilcoxon signed-rank test for small groups was applied. Results were regarded as statistically significant at $p<0.05$.

Comparison of blood pressure values presented in Table I demonstrated absence of significant differences in peripheral and central blood pressure between pre- and post-half marathon conditions. However, after the half marathon race, the runners showed significantly decreased aortic pulse pressure (PP). There was an increase of heart rate (HR) and a decrease of ED (Table II); both variables changed significantly.

The results presented in Table II showed that the half marathon race significantly affected aor- tic stiffness. We noted a decrease of RWTT parallel to the increase of PWV. Central pulse wave form analysis revealed significant increase of Alx75 and PPA. Nevertheless, we observed an insignificant change of SEVR.

Our findings are summarized as follows. First, our data demonstrate that participation in a half marathon race was accompanied with a significant increase in aortic stiffness and wave reflection indexes immediately after the race. Second, blood supply in comparison with the oxygen requirement of the heart evaluated by SEVR was not impaired. Third, peripheral and central blood pressure remained unchanged.

Pulse wave velocity and Alx increase in parallel to cardiovascular risk factors [5]. In healthy young men with compliant arteries, the reflected pressure wave returns to the heart during late systole. This phenomenon protects the microvascular circulation from damage and improves blood flow through the coronary system. The PWV and Alx75 of our study participants, who are amateur runners, significantly rose after the marathon race. This is consistent with the demonstrated increase

Table I. Peripheral and central blood pressure

\begin{tabular}{|c|c|c|c|c|c|}
\hline \multirow[t]{2}{*}{ Variables } & \multicolumn{2}{|c|}{ Pre-half marathon } & \multicolumn{2}{|c|}{ Post-half marathon } & \multirow{2}{*}{$\begin{array}{c}\text { Significance } \\
P \text {-value }\end{array}$} \\
\hline & Mean & $\pm \mathrm{SD}$ & Mean & $\pm \mathrm{SD}$ & \\
\hline $\mathrm{HR}[\mathrm{bpm}]$ & 56 & 13 & 93 & 8 & 0.0002 \\
\hline $\mathrm{SBP}[\mathrm{mm} \mathrm{Hg}]$ & 131 & 11 & 129 & 13 & NS \\
\hline $\mathrm{DBP}[\mathrm{mm} \mathrm{Hg}]$ & 69 & 4 & 64 & 10 & NS \\
\hline $\mathrm{MBP}[\mathrm{mm} \mathrm{Hg}]$ & 90 & 8 & 84 & 10 & NS \\
\hline $\mathrm{PP}[\mathrm{mm} \mathrm{Hg}]$ & 61 & 7 & 65 & 8 & NS \\
\hline SBPao $[\mathrm{mm} \mathrm{Hg}]$ & 116 & 7 & 106 & 10 & NS \\
\hline DBPao [mm Hg] & 69 & 4 & 64 & 10 & NS \\
\hline PPao [mm Hg] & 47 & 4 & 41 & 5 & 0.044 \\
\hline
\end{tabular}
pressure, SBPao - aortic systolic blood pressure, DBPao - aortic diastolic blood pressure, PPao-aortic pulse pressure, NS - not significant.

Table II. Parameters of aortic pulse wave

\begin{tabular}{|c|c|c|c|c|c|}
\hline \multirow[t]{2}{*}{ Variables } & \multicolumn{2}{|c|}{ Pre-half marathon } & \multicolumn{2}{|c|}{ Post-half marathon } & \multirow{2}{*}{$\begin{array}{c}\text { Significance } \\
P \text {-value }\end{array}$} \\
\hline & Mean & $\pm \mathrm{SD}$ & Mean & $\pm \mathrm{SD}$ & \\
\hline $\mathrm{PWV}[\mathrm{m} / \mathrm{s}]$ & 8.2 & 0.84 & 11.87 & 1.58 & 0.000006 \\
\hline RWTT [ms] & 171.0 & 13.62 & 118.9 & 14.3 & 0.000001 \\
\hline Alx75 (\%) & -9.5 & 12.2 & 5.8 & 4.2 & 0.02 \\
\hline PPA (\%) & 129.0 & 5.1 & 156.7 & 7.4 & 0.0006 \\
\hline $\mathrm{ED}[\mathrm{ms}]$ & 383.0 & 77.7 & 274.9 & 19.5 & 0.008 \\
\hline SEVR (\%) & 152.6 & 59.6 & 87.4 & 20.7 & NS \\
\hline
\end{tabular}

Values for $n=8$. PWV - pulse wave velocity, RWTT - reflected wave transit time, Alx75 - augmentation index set to 75 heart beats per minute, PPA - pulse pressure amplification, ED - ejection duration, SEVR - subendocardial viability ratio, NS - not significant. 
of arterial stiffness in response to a rising load level in a clinical exercise test in young men who do not participate in regular exercise training [8]. However, high PWV results in earlier arrival of reflected waves, and thereby augments central systolic pressure during early systole and raises afterload to the heart. There was noted increased PWV and Alx together with central systolic blood pressure (SBP), mean arterial pressure (MAP), and $H R$ in response to an exercise test [9]. In our study, HR increased as well. However, central and peripheral blood pressure, together with MAP, was maintained even if ED decreased.

It was reported that left ventricular end diastolic volume declined immediately after the marathon [10]. On the basis of our study, we suggest that the probability of stroke volume decrease after a half marathon race could be equilibrated by an increase of aortic stiffness and pulse wave reflection indexes. This phenomenon could support the systemic blood pressure level. During exercise, PPA changes because of preferential stiffening of peripheral arteries [8]. In our study, increase of PPA could help eventually maintain blood pressure after the race.

Extremely high endurance effort connected with a marathon race affects cardiovascular system remodeling. It is reported that long-term participants develop large-artery wall stiffness, coronary artery calcification, and acute ischemia-reperfusion injury to the heart, leading to myocardial fibrosis [3]. Thus, the temporary response of the aortic wall to a marathon race seems to be a cardiovascular risk factor but with delayed action.

We conclude that young male amateur runners reveal transient alteration of the aorta's properties after a marathon race. It manifests in the form of great vessels' stiffening and augmented wave reflection parallel to maintained blood pressure.

\section{Conflict of interest}

The authors declare no conflict of interest.

\section{References}

1. Dorobantu M, Tautu OF, Darabont R, et al. Objectives and methodology of Romanian SEPHAR II Survey. Project for comparing the prevalence and control of cardiovascular risk factors in two East-European countries: Romania and Poland. Arch Med Sci 2015; 11: 715-23.

2. Laurent S, Cockcroft J, Van Bortel L, et al. Expert consensus document on arterial stiffness: methodological issues and clinical applications. Eur Heart J 2006; 27: 2588-605.

3. Patil HR, O'Keefe JH, Lavie CJ, et al. Cardiovascular damage resulting from chronic excessive endurance exercise. Mo Med 2012; 109: 312-21.

4. Wassertheurer S, Kropf J, Weber T, et al. A new oscillometric method for pulse wave analysis: comparison with a common tonometric method. J Hum Hypertens 2010; 24: 498-504.
5. Lemogoum D, Flores G, Van den Abeele W, et al. Validity of pulse pressure and augmentation index as surrogate measures of arterial stiffness during beta-adrenergic stimulation. J Hypertens 2004; 22: 511-7.

6. Corrado D, Pelliccia A, Bjørnstad HH, et al. Cardiovascular pre-participation screening of young competitive athletes for prevention of sudden death: proposal for a common European protocol. Consensus Statement of the Study Group of Sport Cardiology of the Working Group of Cardiac Rehabilitation and Exercise Physiology and the Working Group of Myocardial and Pericardial Diseases of the European Society of Cardiology. Eur Heart J 2005; 26: 516-24.

7. Omboni S, Posokhov IN, Rogoza AN. Evaluation of 24hour arterial stiffness indices and central hemodynamics in healthy normotensive subjects versus treated or untreated hypertensive patients: a feasibility study. Int J Hypertens 2015; 2015: 601812.

8. Sharman JE, McEniery CM, Campbell RI, Coombes JS, Wilkinson IB, Cockcroft JR. The effect of exercise on large artery haemodynamics in healthy young men. Eur J Clin Invest 2005; 35: 738-44.

9. Schultz MG, Davies JE, Roberts-Thomson P, et al. Exercise central (aortic) blood pressure is predominantly driven by forward traveling waves, not wave reflection. Hypertension 2013; 62: 175-82.

10. Kean AJ, McCloskey VR, Seghatol FF, et al. Preservation of ventricular function in amateur athletes after completion of a marathon. J Am Soc Echocardiogr 2006; 19: 202-5. 